\title{
Avaliação ergonômica da cabine de um trator florestal
}

\author{
Haroldo Carlos Fernandes ${ }^{1}$, Andréia Bordini de Brito ${ }^{2}$, Luciano José Minetti ${ }^{3}$, Nerilson Terra Santos ${ }^{4}$ Paula \\ Cristina Natalino Rinaldi ${ }^{5}$
}

\section{RESUMO}

Pesquisas desenvolvidas por meio de avaliações ergonômicas e antropométricas contribuem a dar subsídios para novos projetos, com base no dimensionamento de máquinas e equipamentos. Objetivou-se com o presente trabalho realizar uma análise antropométrica de trabalhadores que operam as máquinas de colheita de madeira e avaliar ergonomicamente a cabine do "Feller-Buncher”, com a finalidade de levantar informações necessárias para futuras modificações a serem realizadas com base nos dados obtidos. As análises foram realizadas na empresa florestal Cenibra, localizada no Estado de Minas Gerais. A avaliação antropométrica dos operadores foi realizada por dois conjuntos de medidas, na posição em pé e sentado. Durante as avaliações ergonômicas e a mensuração do posicionamento dos órgãos de comando e campo de visão foram determinadas as distâncias a partir do ponto de referência do assento (PRA) nas três dimensões (x, y e z). De acordo com os resultados, pode-se concluir que há necessidade de melhorias ergonômicas no assento, controle, painel de controle, simbologia de comandos, mostradores e luzes de advertência.

Palavras-chave: Ergonomia, posto de trabalho, máquinas florestais.

\section{ABSTRACT}

\section{Ergonomic evaluation of the operator cabin of a forest tractor}

Studies conducted by anthropometric and ergonomic assessments contribute to aid for new projects based on the design of machines and equipment. The objective of the present work was to perform an anthropometric analysis of workers who operate forest harvest machines and an ergonomic assessment of the operator cabin of a Feller-Buncher, in order to gather information needed for future modifications. Analyses were performed at CENIBRA forestry company in Minas Gerais. The anthropometric evaluation of the operators was conducted by two sets of measures, while standing and sitting. During the ergonomic assessments and measurement of controls positioning and field of view, distances were determined from the seat reference point (ARP) in three dimensions ( $\mathrm{x}, \mathrm{y}$ and $\mathrm{z}$ ). The results showed that there is need for ergonomic improvements in the seat, controls, control panel, symbology commands, dials and warning lights.

Key words: Ergonomics, forestry machines, workstation.

Recebido para publicação em agosto de 2008 e aprovado em julho de 2009

${ }^{1}$ Engenheiro Agrícola, Doutor. Departamento de Engenharia Agrícola da Universidade Federal de Viçosa, Av. PH Holfs, s/n, Campus Universitário, 36570-000, Viçosa, Minas Gerais, Brasil. haroldo@ufv.br

${ }^{2}$ Desenhista Industrial, Doutora. Departamento de Artes e Design da Universidade Federal de Pelotas, Campus Universitário, s/n, 35496010-900, Pelotas, Rio Grande do Sul, Brasil. bordinibrito@yahoo.com.br

${ }^{3}$ Engenheiro Elétrico. Departamento de Engenharia Elétrica e de Produção da Universidade Federal de Viçosa, Av. PH Holfs, s/n, Campus Universitário, 36570-000, Viçosa, Minas Gerais, Brasil. minette@ufv.br

${ }^{4}$ Engenheiro Agrônomo, Doutor. Departamento de Informática da Universidade Federal de Viçosa, Av. PH Holfs, s/n, Campus Universitário, 36570-000, Viçosa, Minas Gerais, Brasil.nsantos@dpi.ufv.br

${ }^{5}$ Engenheira Agrícola, Mestre. Departamento de Engenharia Agrícola da Universidade Federal de Viçosa, Av. PH Holfs, s/n, Campus Universitário, 36570-000, Viçosa, Minas Gerais, Brasil. pcnrinaldi@hotmail.com 


\section{INTRODUÇÃO}

O sistema de colheita de toras longas, também conhecido como sistema "full tree", predominante nos países da América do Norte, utiliza um conjunto mecanizado composto pelo "Feller-Buncher" e "Skidder", sendo o "FellerBuncher" um trator florestal de esteira ou pneus, com cabeçote que realiza o corte e o agrupamento das árvores em feixes, preparando-as para os tratores "Skidders" efetuarem o deslocamento dos feixes até as margens da estrada ou pátio temporário.

Para Lida (2003), a ergonomia é definida como a adaptação do trabalho ao homem. O trabalho abrange as máquinas, os equipamentos e também toda a situação em que ocorre o relacionamento entre o homem e seu trabalho; e a antropometria como o estudo das medidas das várias características do corpo humano. Abrange principalmente o estudo das dimensões lineares, diâmetros, pesos, centros de gravidade do corpo humano e suas partes. Essas medidas estão relacionadas com a média e o desvio padrão, segundo o mesmo autor. A média corresponde simplesmente à média aritmética das medidas de determinada amostra populacional, já o desviopadrão representa o grau de variabilidade dessa medida dentro da amostra escolhida. Com isso, deve-se estar atento a projetos que envolvam os determinados padrões da população.

Grandjean (1998) afirma que a pesquisa antropométrica já evoluiu bastante nos países desenvolvidos, o que não se verifica ainda em nosso sistema de trabalho. Assim, os dados antropométricos utilizados para embasar os projetos de tratores agrícolas e florestais comercializados no Brasil normalmente tem por base os padrões internacionais, devido à carência de informações antropométricas no Brasil.

O correto dimensionamento do posto de trabalho deve permitir que dentro da cabine haja espaço suficiente, de modo que qualquer operador, independentemente de sua compleição física e seu peso, possa adotar posições de trabalho confortáveis e dispor de lugar para pertences pessoais. $\mathrm{O}$ alcance das mãos também é importante, pode ser registrado nos três planos (x, y, z) e se eles forem conjugados entre si, fornecem o traçado de um volume de alcance.

Fontana (2005) realizou uma avaliação ergonômica da cabine de seis modelos de máquinas florestais utilizadas na extração de madeira quanto ao posicionamento de comandos e instrumentos e o campo visual do operador, com base nas características antropométricas do operador brasileiro. O estudo demonstra que o projeto ergonômico da disposição dos comandos nas cabines das máquinas florestais estudadas não é favorável ao conjunto de operadores brasileiros analisados.
A norma NBR-ISO 4252 (2000) estabelece as posições relativas ao assento do trator, aos pedais e ao volante de direção. Segundo Robin (1987), também é necessário estabelecer um espaço livre para a movimentação dos pés e para a troca de postura durante o trabalho.

Dessa forma, objetiva-se com o presente trabalho avaliar aspectos ergonômicos relevantes para o projeto da cabine do trator de colheita florestal "Feller-Buncher" e propor soluções de melhoria ergonômica da cabine.

\section{MATERIAL E MÉTODOS}

Os estudos foram conduzidos na empresa florestal Cenibra, Celulose Nipo-Brasileira, localizada no município de Santa Bárbara, Minas Gerais, situada a 19 58’ 05" S de latitude sul e $43^{\circ} 24^{\prime}$ 57" W de longitude, $732 \mathrm{~m}$ de altitude.

Foi utilizada a máquina florestal "Feller-Buncher" com rodado de esteira, marca Timberjack, modelo 608L (Figura 1).

A população avaliada foi constituída por 21 operadores de "Feller-Bunchers" da empresa.

A coleta de dados para a avaliação ergonômica foi efetuada mediante testes e medições realizados nos operadores e nas máquinas e uso de questionários.

Para a análise antropométrica foram determinadas 33 medidas corporais de 21 operadores, todos operadores de máquinas de colheita florestal.

Na coleta dessas medidas no operador, utilizou-se uma trena e réguas adaptadas, conforme propõe Petroski (2003).

As medidas foram obtidas em três etapas distintas (Figura 2), sendo na primeira realizado o preenchimento da ficha de dados gerais do operador e, posteriormente, a coleta das medidas antropométricas deles, nas posições em pé e sentado.

- $1^{\text {a }}$ Etapa: preenchimento da ficha de dados gerais do operador

- 2 Etapa: coleta das medidas antropométricas dos operadores em pé. As medidas antropométricas na posição em pé foram obtidas por meio de trena adaptada conforme Petroski (2003), que consiste em uma fita métrica com hastes. As medidas obtidas estão esquematizadas na figura 2.

- $3^{\mathrm{a}}$ Etapa: coleta das medidas antropométricas dos operadores sentados - As medidas antropométricas na posição sentado foram obtidas por meio de trena adaptada conforme Petroski (2003), que consiste em uma fita métrica com hastes. As medidas obtidas também estão esquematizadas na Figura 2.

A análise estatística dos dados fez-se com uso dos percentis, que é a separatriz que divide a distribuição da frequência ordenada em 100 partes iguais, a partir do me- 


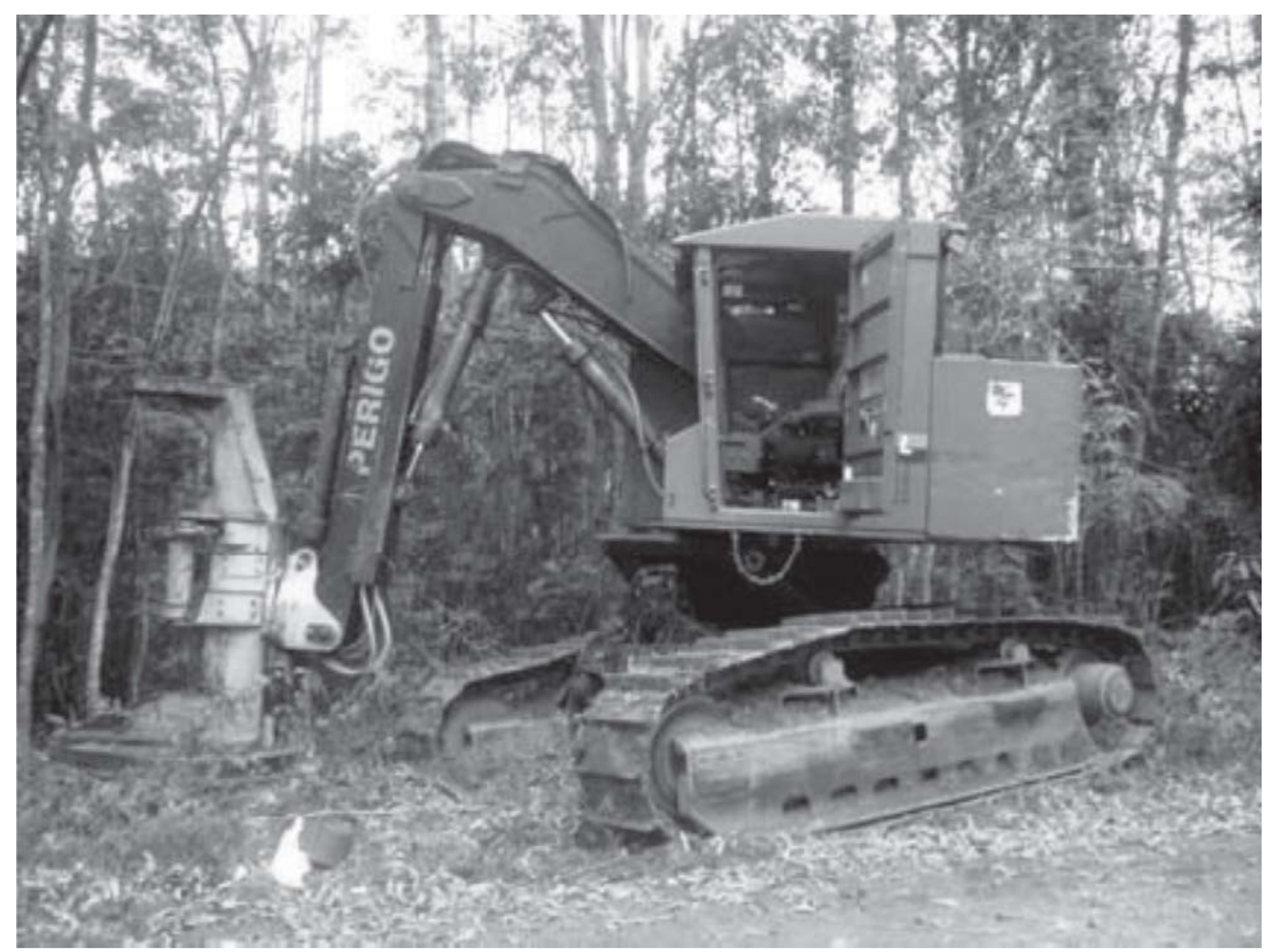

Figura 1. “Feller-Buncher”, marca Timberjack, modelo 608L.

nor para o maior, em relação a algum tipo específico de dimensão corporal.

Ao se determinar as variações antropométricas dos operadores, a mesma análise constou do cálculo dos percentis nos níveis 5, 50 e 95\%. Para as variáveis estudadas nas máquinas nos percentis utilizados, os valores indicados foram 95 e 5\%, dependendo da variável analisada. Isso significa que no percentil menor (5\%) houve possibilidade de $5 \%$ da população estar abaixo do universo pesquisado e, no maior (95\%), 5\% acima. Também foram determinados a média, o desvio-padrão, o coeficiente de variação e o intervalo da medida no qual se encontram 90\% dos indivíduos.

Aplicou-se um questionário para os mesmos operadores sobre símbolos gráficos, visando obter informações sobre o seu grau de conhecimento, que identifica os comandos e controles das operações e manutenção do "Feller-Buncher". Foram fornecidos somente questionários e solicitado ao operador que dissesse qual o significado de cada símbolo. Esse questionário era composto de 16 símbolos, e considerou-se para a avaliação o número de acertos (A), erros (E) e não-respondidos (NR).

A análise das dimensões internas da cabine do "FellerBuncher” foi realizada por meio de medidas a partir do ponto de referência de assento (PRA - SRP “seat reference point”), que, de acordo com o manual de ergonomia para máquinas florestais do Skogforsk (1999), é um ponto situado no plano médio longitudinal central do assento, onde o plano tangencial do encosto intersecciona um plano horizontal. O PRA serve de referência para o dimensionamento de todos os fatores antropométricos em postos de operação.

Na determinação das dimensões da cabine, as medidas foram coletadas com auxílio de esquadro, régua, trena e fita métrica, onde se mensura a distância do PRA até os órgãos de comando nas três dimensões $(\mathrm{x}, \mathrm{y}, \mathrm{z}) \mathrm{e}$, posteriormente, os dados foram representados em gráficos contendo as áreas de máximo e ótimo acesso aos comandos, esquematizados de acordo com o grupo de trabalhadores dessas máquinas.

Durante a avaliação ergonômica foram coletados os dados com o assento em duas posições distintas, classificadas como limites: assento próximo e assento extremo, adotando-se como referência o painel das máquinas em estudo. Dessa maneira realizou-se a avaliação espacial da distribuição dos comandos para as duas posições de assento, atribuindo os conceitos ótimo, muito bom, bom, regular e ruim (Skogforsk, 1999). 


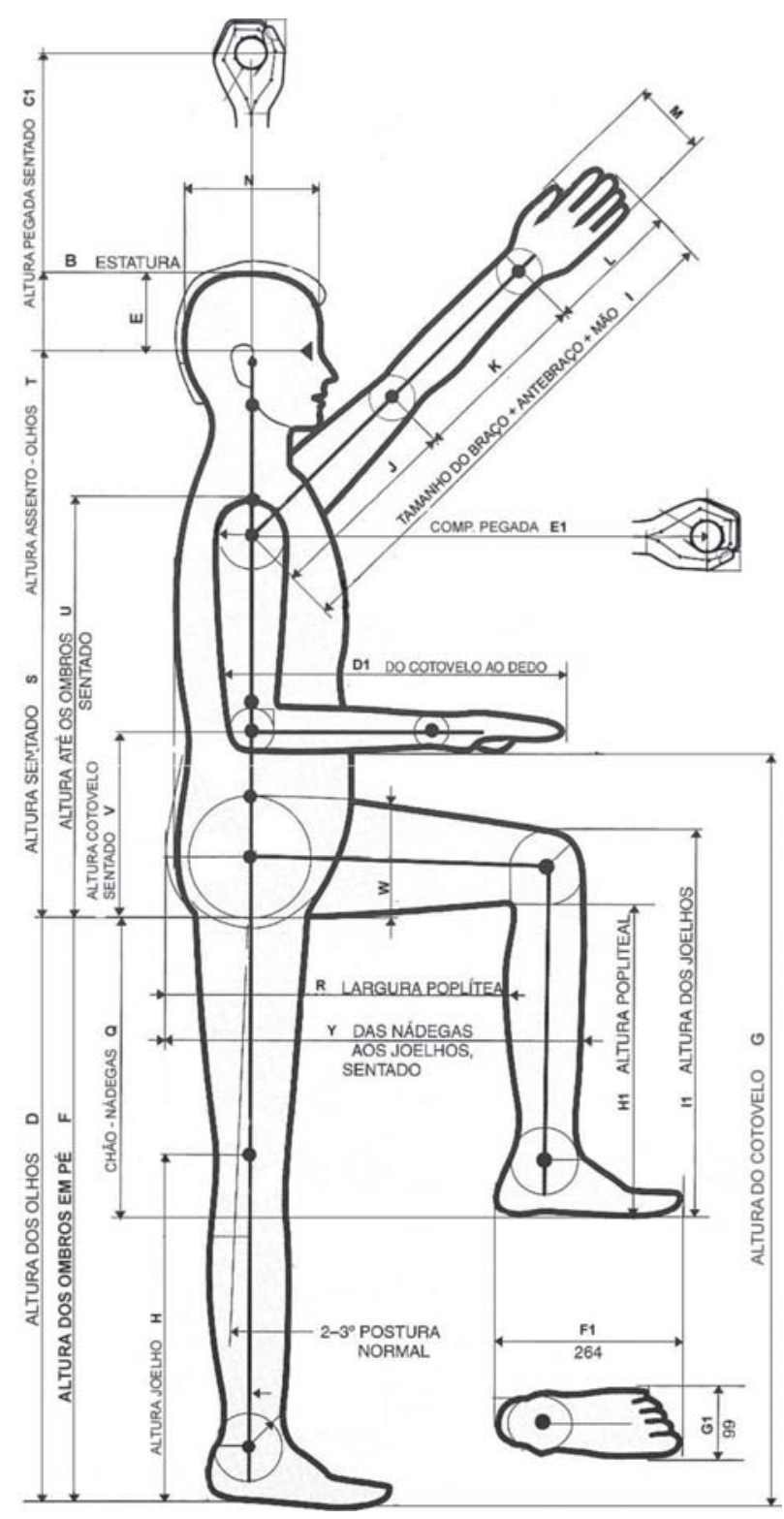

Figura 2. Medidas antropométricas obtidas dos operadores. Fonte: Brito, 2007.

O posto de trabalho da máquina também foi mensurado de acordo com as normas suecas do guia Skogforsk (1999), especificamente proposto para máquinas florestais.

Para determinar o campo visual ótimo e de máxima visão dos operadores quanto ao posicionamento dos instrumentos marcadores (relógios de temperatura de arrefecimento combustível, pressão de óleo, por exemplo), luzes de advertência e mostradores em geral, foram utilizados procedimentos semelhantes aos já descritos. Nessa avaliação foram inseridos os ângulos de visão ótima e máxima, com auxílio do software AutoCad 2000®. Dessa maneira foram avaliados a distribuição espacial dos instrumentos marcadores, as luzes de advertência e os mostradores para as duas posições de assento, atribuindo os conceitos ótimo, muito bom, regular e ruim (Skogforsk,1999).
Nas variáveis relacionadas ao assento das máquinas foram utilizados os valores das medidas antropométricas definidos pelos percentis, conforme Fiedler (1995), Skogforsk (1999), Iida (2003) e Dreyfuss (2003).

\section{RESULTADOS E DISCUSSÃO}

Os dados antropométricos obtidos na amostragem dos operadores avaliados são apresentados na Tabela 1. Nessa tabela também encontram-se analisados os percentis 5, 50 e 95\%, a média, o desvio-padrão e o coeficiente de variação.

Os resultados da avaliação ergonômica da cabine são apresentados na Tabela 2. Eles são baseados em avaliações qualitativas e quantitativas.

Para que a altura livre da cabine seja considerada adequada, Skogforsk (1999) sugere um espaço de $180 \mathrm{~cm}$. As medidas de todas as máquinas foram inferiores à recomendada, no entanto pode-se estimar para este espaço a soma da medida do operador mais alto sentado (S) somada com a altura do chão até as nádegas do maior operador (Q), além dessa medida deve-se adicionar mais espaço, tanto para evitar que a cabeça do operador bata no teto da cabine quando a máquina está operando em terreno acidentado quanto para capacitar o operador a se levantar do assento. O espaço adicional requerido é de, pelo menos, $15 \mathrm{~cm}$. Entretanto, para os operadores mensurados essas diferenças não constituem problemas, pois se se utilizar maiores valores das variáveis $\mathrm{S}+\mathrm{Q}+15$ cm ter-se-á um valor aproximado de $157 \mathrm{~cm}$, o que para os operadores analisados neste levantamento as alturas das cabines estariam adequadas.

No espaço para as pernas e pés a norma sueca aconselha a utilização de $115 \mathrm{~cm}$, as medidas de todas as máquinas mensuradas foram inferiores a este valor; no entanto, nas medidas dos operadores analisados as máquinas estão dentro do estimado, uma vez que esse espaço é utilizado para o dimensionamento das medidas antropométricas coluna-joelho (Y), somadas ao deslocamento de $110^{\circ}$ da altura poplítea (H1), o que para essa amostra o valor estimado seria de $95 \mathrm{~cm}$.

Com relação ao espaço dos joelhos, a norma sugere a utilização de $70 \mathrm{~cm}$; das máquinas analisadas somente uma medida se encontra dentro do recomendado. Para estimar esse valor utiliza-se a medida antropométrica coluna-joelho (Y), acrescida de um espaço de pelo menos 20 $\mathrm{cm}$, onde a cabine ideal deveria ter pelo menos $88 \mathrm{~cm}$ para atender a essa gama de operadores brasileiros. Já para os operadores analisados, o valor encontrado é maior que 68 cm, o que torna inadequado o espaço dos joelhos na cabine analisada.

A largura da cabine é determinada pelo espaço necessário, acomodando o assento juntamente com o descan- 
so de braço e os controles. Uma cabine muito larga reduz a visibilidade nos dois lados. Estima-se que esse valor deve utilizar a maior variável antropométrica, largura total de costas mais braços (B1) com espaço adicional requerido de, pelo menos, $15 \mathrm{~cm}$. O comprimento da cabine segundo a norma é determinado pelo espaço das pernas necessário para o operador endireitar seu corpo e esticar suas pernas. Todas as cabines analisadas encontram-se dentro do valor mínimo.

Na Tabela 3 encontram-se os controles e a visibilidade da cabine do "Feller-Buncher" analisada.

O trator "Feller-Buncher" tem problema de visibilidade para o operador em vários lados da máquina. Na sua frente existem grades de proteção do pára-brisa contra queda de galhos e de um dos lados o cabeçote de corte, que pode estar vazio ou carregado de árvores.

O trator analisado possui somente três faróis na parte superior frontal, dificultando a visão dos operadores no trabalho noturno.

Os pedais não devem obstruir os acessos ao posto de operação, a sua superfície deve ser antideslizante e o seu movimento mais paralelo possível. Os pedais de deslocamento devem cumprir sua função sem exigir grandes esforços.

Na Tabela 4 é apresentada a avaliação espacial das coordenadas x-y e x-z dos 26 (100\%) comandos avaliados.

Analisando-se a distribuição espacial do posicionamento dos comandos com o assento nas duas regiões avaliadas, observa-se que os principais comandos utili-

Tabela 1. Padrão antropométrico dos operadores avaliados

\begin{tabular}{|c|c|c|c|c|c|c|c|}
\hline & \multirow{2}{*}{ Posição } & \multirow{2}{*}{$\begin{array}{l}\text { Média } \\
\text { (cm) }\end{array}$} & \multirow{2}{*}{$\begin{array}{l}\text { Desvio- } \\
\text { Padrão }\end{array}$} & \multirow[t]{2}{*}{ C.V\% } & \multicolumn{3}{|c|}{ Percentil } \\
\hline & & & & & $5 \%$ & $50 \%$ & $95 \%$ \\
\hline \multirow{16}{*}{ 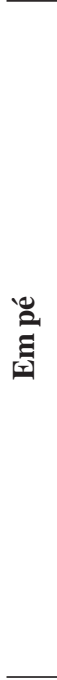 } & 1. Massa corpórea * & 75,9 & 13,3 & 17,5 & 54,0 & 75,9 & 97,7 \\
\hline & 2. Estatura & 175,0 & 4,8 & 2,7 & 167,1 & 175,0 & 182,9 \\
\hline & 3. Altura total (braço levantado) & 217,8 & 9,1 & 4,2 & 202,8 & 217,8 & 232,8 \\
\hline & 4. Altura dos olhos & 166,3 & 4,8 & 2,9 & 158,4 & 166,3 & 174,3 \\
\hline & 5. Altura do ouvido & 163,3 & 4,6 & 2,8 & 155,7 & 163,3 & 170,9 \\
\hline & 6. Altura ombro & 148,2 & 5,6 & 3,7 & 139,0 & 148,2 & 157,3 \\
\hline & 7. Altura cotovelo & 113,9 & 8,3 & 7,3 & 100,2 & 113,9 & 127,5 \\
\hline & 8. Altura joelho & 50,6 & 2,4 & 4,7 & 46,6 & 50,6 & 54,5 \\
\hline & 9. Braço + antebraço + mão & 76,5 & 4,0 & 5,2 & 69,9 & 76,5 & 83,0 \\
\hline & 10. Tamanho do braço & 57,8 & 3,0 & 5,1 & 52,9 & 57,8 & 62,7 \\
\hline & 11. Tamanho do antebraço & 27,5 & 1,7 & 6,3 & 24,7 & 27,5 & 30,3 \\
\hline & 12. Tamanho da mão & 20,0 & 1,4 & 7,0 & 17,7 & 20,0 & 22,3 \\
\hline & 13. Largura mão & 11,9 & 0,9 & 7,7 & 10,4 & 11,9 & 13,3 \\
\hline & 14. Largura cabeça & 19,8 & 1,1 & 5,4 & 18,0 & 19,8 & 21,6 \\
\hline & 15. Largura tórax, entre axilas & 36,0 & 3,1 & 8,7 & 30,9 & 36,0 & 41,1 \\
\hline & 16. Largura quadril & 35,9 & 2,9 & 8,1 & 31,0 & 35,9 & 40,6 \\
\hline \multirow{18}{*}{ 胥 } & 17. Chão - nádegas & 43,5 & 4,7 & 10,9 & 35,7 & 43,5 & 51,3 \\
\hline & 18. Largura poplítea & 43,1 & 2,3 & 5,4 & 39,3 & 43,1 & 47,0 \\
\hline & 19. Altura sentado & 84,0 & 3,2 & 3,8 & 78,7 & 84,0 & 89,2 \\
\hline & 20. Altura assento-olhos & 73,5 & 5,1 & 6,9 & 65,1 & 73,5 & 81,8 \\
\hline & 21. Altura até os ombros sentado & 54,3 & 3,9 & 7,2 & 47,9 & 54,3 & 60,8 \\
\hline & 22. Altura do cotovelo sentado & 20,9 & 5,2 & 25,0 & 12,3 & 20,9 & 29,5 \\
\hline & 23. Altura da coxa & 15,8 & 1,7 & 10,7 & 13,0 & 15,8 & 18,6 \\
\hline & 24. Comprimento do antebraço & 28,9 & 1,5 & 5,3 & 26,3 & 28,9 & 31,4 \\
\hline & 25. Coluna - joelho & 58,2 & 3,1 & 5,3 & 53,1 & 58,2 & 63,2 \\
\hline & A1. Largura dos ombros & 42,7 & 2,6 & 6,1 & 38,4 & 42,7 & 47,0 \\
\hline & B1. Largura total costas + braços & 51,4 & 3,7 & 7,3 & 45,2 & 51,4 & 57,6 \\
\hline & C1. Altura de pegada sentado & 117,4 & 6,1 & 5,2 & 107,3 & 117,4 & 127,5 \\
\hline & D1. Comp. cotovelo ao dedo & 47,8 & 1,9 & 3,9 & 44,7 & 47,8 & 50,9 \\
\hline & E1. Comp. pegada - costas & 68,6 & 4,7 & 6,9 & 60,8 & 68,6 & 76,4 \\
\hline & F1. Comprimento do pé descalço & 27,3 & 0,9 & 3,2 & 25,7 & 27,3 & 28,9 \\
\hline & G1. Largura do pé descalço & 11,1 & 0,6 & 4,9 & 10,0 & 11,1 & 12,0 \\
\hline & H1. Altura popliteal & 46,6 & 1,9 & 4,1 & 43,5 & 46,6 & 49,8 \\
\hline & I1. Altura dos joelhos & 56,9 & 2,6 & 4,6 & 52,5 & 56,9 & 61,1 \\
\hline
\end{tabular}

* Massa corpórea em kg. 
Tabela 2. Dimensões cabine em relação ao PRA

\begin{tabular}{|c|c|c|}
\hline \multirow{2}{*}{$\begin{array}{l}\text { Medidas em cm } \\
\text { Posicionamento assento }\end{array}$} & \multicolumn{2}{|c|}{ Timberjack 608L } \\
\hline & próximo & extremo \\
\hline A-Altura livre & \multicolumn{2}{|c|}{162,0} \\
\hline B - Painel traseiro na altura da cabeça & 42,0 & 39,0 \\
\hline C - Espaço para as pernas (e pés) & 98,0 & 112,0 \\
\hline D - Espaço para os joelhos & 68,0 & 73,0 \\
\hline E - Painel frontal na altura do descanso dos braços & 32,0 & 36,0 \\
\hline Largura cabine & \multicolumn{2}{|c|}{86,0} \\
\hline Comprimento cabine & \multicolumn{2}{|c|}{120,0} \\
\hline Dist. pedais até carcaça & \multicolumn{2}{|c|}{20,0} \\
\hline Dist. banco até a carcaça & $21,0 \mathrm{~d}$ & 21,0 e \\
\hline
\end{tabular}

$\mathrm{d}$ = direita; $\mathrm{e}$ = esquerda.

Tabela 3. Controles e visibilidade da cabine da máquina avaliada.

\begin{tabular}{lc}
\hline Medidas & Timberjack 608L \\
\hline Comprimento x largura do & 73,0 x 9,0 \\
painel controle (cm) & 26 \\
Número de funções (un) & $72,0 \times 95,0$ \\
Visibilidade frontal (cm) & - \\
Visibilidade lateral direita (cm) & $68,0 \times 95,0$ \\
Visibilidade lateral e Esquerda (cm) & 44,0 \\
“joysticks” ao PRA (cm) & \\
\hline
\end{tabular}

Tabela 4. Distribuição espacial dos 26 comandos da máquina avaliada nas coordenadas $\mathrm{x}-\mathrm{y}$ e $\mathrm{x}-\mathrm{z}$

\begin{tabular}{lcc}
\hline Timberjack 608L & \multicolumn{2}{c}{ Posicionamento do assento } \\
\cline { 2 - 3 } Conceito & Próximo & Extremo \\
\hline Ótimo & $10(38,4 \%)$ & $7(26,9 \%)$ \\
Muito bom & $5(19,2 \%)$ & - \\
Bom & $4(15,4 \%)$ & $5(19,2 \%)$ \\
Regular & $2(07,8 \%)$ & $1(03,9 \%)$ \\
Ruim & $5(19,2 \%)$ & $13(50,0 \%)$ \\
Total & $26(100,0 \%)$ & $26(100,0 \%)$ \\
\hline
\end{tabular}

zados durante a jornada de trabalho, no caso os “joysticks”, indiferente do posicionamento do assento, receberam o conceito de “ótimo”, fato explicado por estarem fixos ao assento da máquina.

O posicionamento de assento próximo, o que é pouco comum na máquina que tem o espaço restrito, na maioria dos comandos $(38,4 \%)$ recebeu o conceito “ótimo”, encontram-se os "joysticks" de comando do cabeçote de corte dos lados esquerdo e direito, luz de advertência do nível óleo do hidráulico, luz de filtro óleo do hidráulico, pressão do óleo hidráulico, nível do líquido de refrigeração, luzes frontais, luzes laterais, controle do freio, balanço e controle de velocidade. Nenhum comando na posição "extremo" recebeu o conceito muito bom, essa posição de assento é a mais utilizada por mais de $90 \%$ dos operadores, uma vez que o posicionamento do assento próximo reduz muito o espaço destinado às pernas.
Os pedais esquerdo e direito, frente e trás, receberam conceito "ruim" nas duas situações avaliadas, exigindo um esforço adicional para que o operador consiga manipulá-los. Cinquenta por cento dos comandos receberam conceito "ruim” com a posição extremo. Ressaltase, porém, que a maioria dos comandos contidos neste contexto, a não ser os pedais esquerdo e direto, é instrumento medidor, luzes de advertência e indicadores, não necessitando acionamento, mas somente observação.

Observa-se que no posicionamento do assento localizado em "próximo” e “extremo” existe uma diferença na distribuição dos comandos, quando se considera a somatória dos conceitos “ótimo”, “muito bom” e "bom”, a maior porcentagem foi obtida com o posicionamento em próximo (73\%).

Considerando a área de ótima e máxima visão dos instrumentos luzes de advertência e medidores (Tabela 5), observou-se um campo visual diferenciado em função do posicionamento do assento. O próximo a 27,2\% obteve o conceito regular e $72,8 \%$ conceito ruim. Para o posicionamento extremo apenas $9,0 \%$ receberam conceito bom, 54,5\% regular e $36,5 \%$ ruim. O posicionamento extremo do assento nessa máquina facilita a visualização dos instrumentos e medidores, porém dificulta o acionamento de comando, como foi comentado anteriormente.

O levantamento dos dados das variáveis dos assentos do trator mensurado encontra-se na Tabela 6, em com-

Tabela 5. Localização no campo visual das 11 funções visuais no painel da máquina avaliada

\begin{tabular}{lcc}
\hline \multirow{2}{*}{$\begin{array}{l}\text { Timberjack 608L } \\
\text { Conceito }\end{array}$} & \multicolumn{2}{c}{ Posicionamento do assento } \\
\cline { 2 - 3 } & Próximo & Extremo \\
\hline Ótimo & - & - \\
Muito bom & - & - \\
Bom & - & $1(09,0 \%)$ \\
Regular & $3(27,2 \%)$ & $6(54,5 \%)$ \\
Ruim & $8(72,8 \%)$ & $4(36,5 \%)$ \\
Total & $11(100,0 \%)$ & $11(100,0 \%)$ \\
\hline
\end{tabular}


paração com os valores indicados com base nas medidas antropométricas dos operadores analisados. Um dos requisitos mais importantes a ser satisfeito consiste em assegurar que o operador fique em uma posição confortável sem ter que modificar sua posição de trabalho e ser obrigado a manobrar simultaneamente dois comandos, colocados diante dele, em posições extremas. $\mathrm{O}$ assento deve ter ajuste em altura, distância e comprimento. A inclinação assento/encosto deve ser ajustável de 90 a 110 graus (Skogforsk, 1999).

Tabela 6. Levantamento de dados das variáveis do assento do "Feller-Buncher" e valores indicados de acordo com o levantamento antropométrico da população de operadores mensurados

\begin{tabular}{lc}
\hline Itens de inspeção assento & Timberjack 608L \\
\hline Assento estofado & sim \\
Altura do assento mínimo (cm) & 55,0 \\
Altura do assento máximo (cm) & 61,0 \\
Acionamento fácil de regulagem da altura & não \\
Posicionamento assento próximo & 71,0 \\
Posicionamento assento extremo & 75,0 \\
Largura do assento (cm) & 48,0 \\
Comprimento do assento (cm) & 44,0 \\
Forma assento (plana, côncava, convexa) & côncava \\
Borda anterior arredondada & sim \\
Inclinação do assento & não \\
Material de revestimento (tipo, cor) & estofado cinza \\
\hline Encosto & \\
\hline Largura do encosto (cm) & 45,0 \\
Altura do encosto (cm) & 55,0 \\
Tipo de apoio dorsal (só lombar, mediano, & \\
apoio de todo dorso) & total + cabeça \\
Forma de apoio dorsal (convexo, plano, & côncavo \\
acomp. curvatura da coluna) & \\
\hline Assento - Encosto & trapézio \\
\hline Possui espaço livre entre assento encosto & não \\
Ângulo assento encosto (graus) & simel \\
\hline Apoio braços & lado/frente \\
\hline Altura do apoio (cm) & estofado \\
Largura do apoio (cm) & $10^{\circ}$ \\
Comprimento do apoio (cm) & 22,0 \\
Apoio fixo/móvel & móvel \\
Tipo de mobilidade frente/lado/vertical/ & \\
horizontal & \\
Tipo de revestimento & \\
Inclinação do apoio ( ${ }^{\circ}$ ) & \\
\hline Basença de batente para o apoio & \\
\hline Massento & \\
\hline
\end{tabular}

O trator mensurado não possui ajuste de altura de assento dentro dos valores indicados com base nas medidas antropométricas dos operadores analisados. A largura e o comprimento do assento são acima do valor indicado. Para determinação das variáveis de altura, comprimento e largura de assento tomam-se como referência as medidas antropométricas da altura e largura poplítea e largura dos quadris, respectivamente.

$\mathrm{O}$ trator analisado tem o encosto com a altura dentro do indicado, enquanto a largura do encosto está acima. Para largura do encosto a variável antropométrica é a largura do quadril no percentil 95\%.

Segundo Skogforsk (1999), o recomendado é que o ângulo assento-encosto tenha variação, no caso todas as máquinas mensuradas possuem ângulo fixo. A altura de descanso para os braços deve ser variável.

Os suportes de braço oferecem apoio, não restringindo os movimentos, podendo-se classificar como ergonomicamente bom nesse aspecto, segundo as diretrizes ergonômicas.

O assento permite variação da distância em relação ao painel, em função do deslizamento, e da base do assento, em trilhos.

\section{CONCLUSÕES}

De acordo com os resultados obtidos neste estudo verificou-se a necessidade de melhorias nos seguintes aspectos ergonômicos:

Acesso à cabine - melhor distribuição dos degraus e hastes, necessitando no mínimo de três pontos para o apoio.

Assento - recomendação e adequação às medidas antropométricas dos operadores mensurados com relação à regulagem e aos ajustes.

Controles - alteração de controles por categoria de atividade no que diz respeito à forma e ao material.

Painel de controle - distribuição ordenada do painel e mostradores por tarefa e lógica de sequência operacional nos limites das áreas de ótimo e máximo alcance de visão.

Simbologia e nomenclatura de comandos - são necessárias formas simples e linguagem clara para garantir a confiabilidade de leitura e entendimento.

A cabine da máquina em questão não atende às necessidades antropométricas dos operadores brasileiros.

\section{REFERÊNCIAS}

Brito AB (2007) Avaliação e redesenho da cabine do "FellerBuncher” com base em fatores ergonômicos. Tese de doutorado. Universidade Federal de Viçosa, Viçosa. 151p.

Dreyfuss H (2003) Designing for people. $3^{\text {a }}$ ed. Canadá, Allworth Press, Designing Management Intitute. 284p. 
Fiedler NC (1995) Avaliação ergonômica de máquinas utilizadas na colheita de madeira. Dissertação de mestrado. Universidade Federal de Viçosa, Viçosa. 126p.

Fontana G (2005) Avaliação ergonômica do projeto interno de cabines de forwarders e skidders. Dissertação de mestrado. Universidade de São Paulo, ESALQ, Piracicaba. 80p.

Grandjean EO (1998) Assento de Trabalho. In: Manual de ergonomia: Adaptando o Trabalho ao Homem. $4^{\text {a }}$ ed. Porto Alegre, Bookman. p.60-72.

Iida I (2003) Ergonomia: projeto e produção. 9a ed. São Paulo, Edgard Blücher. 465p.
International Organization for Standardization(2000) Agricultural tractors - operator's seating accommodation - dimensions. ISO 4252-2000, Genève. 17p.

Petroski EL (2003) Antropometria: Técnicas e padronizações. 2a ed. Porto Alegre, Pallotti. 160p.

Robin P (1987) Segurança e ergonomia em maquinaria agrícola. São Paulo, IPT, FUNDACENTRO. 24p.

Skogforsk (1999) The forestry research institute of Sweden. Ergonomic guidelines for forest machines. Uppsala, Swedish National Institute for Working Life. 86p. 